\title{
EL FUNCIONAMIENTO DEL ADVERBIO Y LA SUPERACIÓN DE LOS LÍMITES ORACIONALES
}

Catalina Fuentes Rodríguez

Es casi un tópico hablar de la problemática que el adverbio presenta en cuanto a su sistematización, ya que es una categoría en la que se han incluido elementos de diverso comportamiento, con la consiguiente insatisfacción que ello plantea. De ahí las continuas revisiones a esta cuestión, y la multitud de trabajos que intentan «clasificar» el adverbio, tales como los análisis de Buyssens ${ }^{1}$, Schlyter ${ }^{2}$, P. Carbonero ${ }^{3}$, P. Domínguez de Rodríguez-Pasqués ${ }^{4}$, Feuillet ${ }^{5}$, etc.

Otros han tendido a estudiar algunos elementos que presentaban problemas específicos. Así, por ejemplo, Fraser ${ }^{6}$, Shanon ${ }^{7}$, Horn ${ }^{8}$, entre otros, con respecto a even. O Chai-Söng ${ }^{9}$ con los deícticos.

Interesados nosotros por este mismo asunto, estamos llevando a cabo una investigación de la que las siguientes apreciaciones y comentarios forman parte 461-463.

1 E. Buyssens: «La classification des adverbes». Revue Roumaine de Linguistique, 20, 1975, pp.

2 S. Schlyter: «Une hiérarchie d'adverbes en français». Recherches linguistiques, 1972, no 1, pp. 139-158.

3 P. Carbonero Cano: «Criterios para una clasificación funcional de los adverbios». Revista de la Sociedad Española de Lingüística, 8-1, 1978, pp. 169-197.

4 P. Domínguez de Rodríguez-Pasqués: «Morfología y sintaxis del adverbio en -mente-» Actas III Congreso Internacional de Hispanistas, México, 1970, pp. 293-303.

5 J. Feuillet: «Peut-on parler d'une classe de l'adverbe?». La Linguistique, 17, 1, 1981, pp. 19-27.

6 B. Fraser: «An analysis of 'even' in English». Ch. J. Fillmore-D. T. Langendoen (eds): Studies in Linguistic Semantics, Holt, Rinehart \& Winston, 1971, pp. 150-178.

7 B. Shanon: «Even, only and almost hardly». Studies in Language, 2:1, 1978, pp. 35-70.

8 L. R. Horn: «A presuppositional analysis of only and even». Papers from the 5 th. Regional Meeting Chicago Linguistic Society, 1969, pp. 98-107.

9 H. Chai-Söng: «Les adverbes de temps en -ment en tête de la phrase». Le Français Moderne, 43,1975 , n. 2, pp. 148-157. 
integrante. Debido a la complejidad del tema, no podremos sino esbozar algunos aspectos, hacer una aproximación a la cuestión. Nos interesa exponer a la consideración de todos algunos puntos que pueden arrojar alguna luz sobre el problema tratado y que, en nuestra opinión, no han sido suficientemente desarrollados.

Para ello, observemos, como punto de partida, el comportamiento distinto de unidades como bien, probablemente, hasta o además, todas ellas incluidas en la categoría adverbio. Veámoslas en enunciados completos:

/1a/: «Cuando llegamos, ya los abuelos estaban bien instalados»

/2a/: «Me encuentro muy bien»

/3a/: «Probablemente estará ahí»

/4a/: «Hasta los más inútiles pueden aprobar ese examen»

/5a/: «No quiero decirte nada más. Además, ya estoy cansada»

También podemos incluir aquí sin embargo, considerado tradicionalmente como locución adverbial o incluso como conjunción:

/6a/: «Él me había prometido que me regalaría aquel libro. Sin embargo, llegó el día y yo no lo tenía».

Estos ejemplos pueden servirnos como ilustración de toda la gama de posibilidades funcionales que se encierran bajo la etiqueta adverbio, así como nos evidencian lo incierto del límite entre estos y las conjunciones, partículas ya puramente gramaticales de contenido relacional. Desde el elemento funcionalmente secundario pero con contenido semántico pleno (adverbio) al útil gramatical de enlace (conjunción) hay diversos pasos graduales que no se han atendido lo bastante en las gramáticas, pero la lengua los rellena con diversas unidades. Todos ellos son «adverbios», pero con un comportamiento muy peculiar cada uno.

Esta categoría había quedado establecida por la Academia como la que incidía en el verbo, adjetivo u otro adverbio, o como categoría terciaria, siguiendo la teoría de los rangos de $\mathrm{O}$. Jespersen ${ }^{10}$. Este último planteamiento es utilizado por P. Carbonero que lo entiende en el sentido de ser «incidencia de incidencias» ${ }^{11}$. Esta caracterización permite encontrar un valor unitario a las diversas incidencias particulares que el adverbio puede tener, incluidas las de modificar un sintagma nominal o una oración. Las han reconocido también muchos otros como Feuillet ${ }^{12}$, Ducrot ${ }^{13}$ o Priyatkina ${ }^{14}$.

Aplicando los criterios tradicionales, sólo bien, de entre los expuestos, sería adverbio, ya que es el único que incide en un verbo o un adjetivo. Los demás no, ya que probablemente engloba a toda la oración, indicando una modalidad; hasta a un sintagma nominal: hasta los más inútiles. Y los otros dos, además y sin embargo, aparecen a principio de frase formando un grupo entonativo inde-

10 O. Jespersen: La filosofía de la gramática. Barcelona, Anagrama, 1975.

11 P. Carbonero: op. cit., p. 183.

12 J. Feuillet: op. cit.

13 O. Ducrot: «Analyses pragmatiques». Communications, 32, 1980, pp. 11-60.

14 A. F. Priyatkina: «Ob otilichii soyuza ot drugikh svyazuyushchikh slov» (Diferencias entre la conjunción y otras palabras conectoras), Russkii yazyk v shkole: 1977, 64, 4, pp. 102-107. 
pendiente, separados por pausas del resto de la oración. Además, los hemos puesto con un enunciado anterior, ya que si iniciamos el ejemplo en estos dos términos:

?/5b/: «Además, ya estoy cansada»

?/6b/: «Sin embargo, llegó el día y yo no lo tenía», las oraciones no tienen sentido.

Necesitan, pues, un enunciado que preceda, con el que conectan aquel al que pertenecen, indicando mera adición en el primero de los casos o una oposición en el segundo. Su misión es parecida, pues, a la de las conjunciones. Tanto es así que este último elemento ha sido incluido con bastante frecuencia entre las conjunciones coordinadas adversativas, como ya hemos dicho. Gili Gaya consideraba este tipo de unidades como una clase de «enlaces extraoracionales» ${ }^{15}$, es decir, de recursos de que se vale el idioma para dar expresión gramatical a relaciones que van más allá de la oración y que establecen «una coherencia representativa, lógica o afectiva, una trabazón psíquica de orden superior» ${ }^{16}$. En vista de esto, es evidente que no puede explicarse por completo con un criterio único todas estas posibilidades funcionales.

S. Greenbaum ${ }^{17}$, sin embargo, utilizó para el inglés una distinción bastante atrayente. Él los dividía en «adjuncts, conjuncts and disjuncts». Para llegar a esta distinción Greenbaum utilizaba una serie de criterios o pruebas sintácticas o distribucionales no todas rentables en español ${ }^{18}$. Así, adaptándolo a nuestro idioma y precisando sus valores, podríamos decir que esos grupos se caracterizan por lo siguiente:

Los adjuntos son aquellos elementos que inciden en el verbo u otro segmento. Tienen una función sintáctica dentro de la oración y no pueden aparecer aislados por pausas, a no ser por motivos de énfasis. A veces son afectados por procedimientos de formulación del contenido oracional, como la negación. Por ejemplo, hasta no puede aparecer en oraciones negativas. Es un término de polaridad positiva, como lo llama I. Bosque ${ }^{19}$.

En este grupo entrarían elementos como bien, felizmente, gravemente, desentonadamente, etc. Así también algunos otros como hasta, incluso, al menos, etc., que, como podemos observar, son de naturaleza muy distinta a los primeros. En estos el aporte semántico se dirige al elemento modificado sólo. Así bien en la oración 2, va modificando al sintagma verbal me encuentro. En el caso de bien instalados $(/ 1 /)$, su ámbito de incidencia es el adjetivo instalados. Y sobre

15 S. Gili Gaya: Curso Superior de Sintaxis Española. Barcelona, Vox, 10a. edic., 1972, cap. XXIV.

16 Idem. p. 325

17 S. Greenbaum: Studies in English adverbial usage. London, Longman, 1970.

18 Véase S. Greenbaum: op. cit., pp. 18-22. Y mi artículo: «Pragmática y relación intratextual: el caso de hasta, incluso y ni siquiera», a aparecer en E.L.U.A., 4. En él trato la adecuación de estas pruebas a nuestra lengua, aplicándolas sobre todo a los adverbios concretos que aparecen en el título.

19 I. Bosque: Sobre la negación. Madrid, Cátedra, 1980, cap. 1. Pero él no trata específicamente este elemento. Y véase también, y para todas las cuestiones referidas a este elemento, mi artículo citado en la nota anterior. 
dichos elementos recae su contenido de bondad. Pero en los segundos se trata de un contenido presuposicional que apunta al contexto anterior o posterior, o bien a un conocimiento extralingüístico común a hablante y oyente.

En la /4/: «Hasta los más inútiles pueden aprobar ese examen», afirmamos que el sintagma "los más inútiles" puede satisfacer el predicado verbal propuesto. Pero al mismo tiempo presuponemos que hay otros elementos de la misma serie que podrían aparecer como sujetos del verbo "pueden aprobar". Es más, sorprende que el enunciado aquí: "los más inútiles" satisficieran esa condición, porque se entiende como el menos probable.

Así pues, la pragmática y la presuposición conforman el contenido de una unidad tradicionalmente considerada adverbio. Estas unidades necesitan del contexto o de la realidad para significar. Priyatkina es el único que recoge este valor, considerándolas «palabras híbridas», elementos que tienen función conectiva aparte de la de modificadores de otra unidad concreta.

De esta manera la variedad de elementos con valor conectivo agrupa tres tipos: las llamadas palabras «híbridas» que conjugan esta función con la que su categoría les marca; las conjunciones, y una serie de palabras auxiliares cuya misión es conectar, es decir, nuestros enlaces ${ }^{20}$.

Al mismo tiempo cabe observar, que frente a la libertad de movimientos de los primeros, tenemos la fijeza de algunos del grupo 2, como hasta. Así, podemos decir la oración /1/ y /2/ de esta manera:

/1b/: «Cuando llegamos, ya los abuelos estaban instalados bien»

$/ 2 \mathrm{~b} /$ : «Muy bien me encuentro».

Pero no podemos hacer lo mismo con la de hasta:

*/4b/: «Los más inútiles — hasta / pueden aprobar ese examen» ya que en todo caso habría que entenderla incidiendo en el verbo:

/4c/: «Los más inútiles / hasta $\rightarrow$ pueden aprobar ese examen».

Pero también hay otros que sí son móviles. Por ej. incluso, que en muchos sentidos es igual a hasta. Así las oraciones $/ 4 \mathrm{~d} / \mathrm{y} / 4 \mathrm{e} /$ :

$/ 4 \mathrm{~d} /:$ «Incluso $\rightarrow$ [los más inútiles] pueden aprobar ese examen»

/4e/: «[Los más inútiles]- incluso / pueden aprobar ese examen».

El problema se complica cuando tocamos los otros grupos: probablemente, además, sin embargo, en nuestros ejemplos. En ellos la definición tradicional resulta insuficiente. Y es lo que ha hecho que algunos autores los llamen adverbios de frase o conjunciones.

Para S. Greenbaum estos dos grupos se caracterizan por aparecer entre pausas, separados entonativa y funcionalmente del resto de la oración. No modifican a ningún elemento de la misma, ni son, a su vez, afectados por ningún procedimiento que opere dentro de ella, por ej. la rematización o la negación. Así, mientras bien puede ser focalizado por la interrogación,

/7/: «¿El enfermo está bien o mal?», los otros no admiten dicha prueba. Así, los ejs. $/ 3 \mathrm{~b} /, / 5 \mathrm{c} / \mathrm{y} / 6 \mathrm{c} /$ : 
*/3b/: «¿Él estará ahí probablemente o seguramente?»

* $/ 5 \mathrm{c} /$ : « ¿Estás cansada ya además o ahora bien?»

*/6c/: «¿Llegó el día sin embargo o además?»

Pero entre los adjuntos también hay algunos que no lo admiten. Por ej. incluso no puede ser focalizado, a no ser que lo que se resalte sea el grupo formado por dicho elemento y su término o ámbito. En

$18 \mathrm{a} /$ : «Incluso Juan vino a la fiesta»

la prueba sería:

*/8b/: « ¿Vino a la fiesta Juan incluso o sólo?», que no parece muy aceptable. Pero sí:

/8c/: «¿Vino a la fiesta incluso Juan o sólo Juan?»

Por lo tanto la distinción que proponemos en los adjuntos, entre aquellos que tienen un contenido designativo y los que sustentan un valor presuposicional, se hace más latente. Además, estos últimos se relacionan con los adverbios llamados oracionales, con los «conjuncts» de Greenbaum, en que también suponen una conexión, aunque sea por referencia, ya que no va dirigida al enunciado anterior, sino a la realidad extralingüística.

Los disjuntos y enlaces, además, suelen estar al inicio de la oración (los primeros con movilidad) pero entre ellos se establece una diferencia fundamental: los disjuntos marcan una evaluación por parte del hablante ante lo que dicen y otros, los conjuntos o «enlaces conjuntivos» como nosotros los llamamos, sirven para conectar esa oración con el enunciado previo. Estos últimos no pueden aparecer iniciando conversación, ya que su misión es señalar contextualmente hacia lo precedente, con lo que se une.

Por lo tanto, podríamos hablar de la existencia, en términos nuestros, de elementos marcadores de la modalidad de la frase: así probablemente, y por otro lado de conectores de enunciados: además y sin embargo en nuestro ejemplo. El funcionamiento del adverbio, pues, rebasa los límites de la estructura sujeto-verbo, para marcar aspectos marginales: la actitud del hablante ante lo expresado por la oración (modalidad) o bien pueden servir de marcadores de progresión o continuación del discurso.

19/: «No protesto contra la hora de salida. Más aún, me gusta».

En este caso lo que une este elemento, más aún, son dos actos enunciativos: «digo X y más aún, digo Y.».

Ahora bien, esto nos lleva a otra conclusión que no había considerado sistemáticamente ninguno de estos autores y que nos parece clave: sólo un planteamiento que se atenga a la realidad textual puede acoger estas últimas unidades que, si bien desde el punto de vista de la gramática oracional son adverbios, categoría terciaria, tienen misión discursiva: relacionar unidades completas de pensamiento, o unidades comunicativas. La diferencia que hay entre además e $y$, o entre sin embargo y pero es que los «adverbios» pueden aparecer con conjunciones, mientras que estas no pueden agruparse entre sí. Podemos decir:

/10/: «El cine es muy aburrido y caro. $Y$ además, no tengo yo hoy ganas de salir de casa», o 
/11a/: «Casi estoy segura de que lo ví. Pero, sin embargo, siempre cabe la posibilidad de equivocarse».

Pero no:

*/11b/: «Casi estoy segura de que lo ví. Y pero siempre cabe la posibilidad de equivocarse».

Al mismo tiempo, los enlaces conjuntivos matizan aún más el sentido de la relación que la conjunción.

Por lo tanto, tras este recorrido en que se nos ha revelado el diferente funcionamiento de los adverbios, podríamos formularlo de la siguiente manera que proponemos como más completa y ajustada al objeto, según nuestros criterios:

La realidad que se incluye tradicionalmente bajo la categoría «adverbio», categoría que no discutimos ya que se formula dentro de una gramática de la oración en que es perfectamente posible como término terciario (en sentido amplio), funciona en dos planos:

- plano textual, donde se acogen los enlaces conjuntivos, elementos cuya misión es la conexión entre enunciados, punto este en el que investigamos actualmente.

- Y un plano oracional dentro del cual se situan los adjuntos y disjuntos. Llamaremos adjuntos a los tradicionalmente considerados adverbios, elementos con una función sintáctica dentro de la frase, como modificadores de un elemento en concreto o englobadores de un sintagma. Dentro de ellos hemos visto que se distinguen dos grupos:

a) los que tienen contenido léxico pleno, y

b) otros cuyo contenido es presuposicional, del tipo de hasta, ni siquiera, al menos, sólo... Estos hacen relación al contexto sintagmático anterior o a la realidad extralingüística, punto este no reconocido por la crítica. Por lo tanto, sólo son explicables desde un punto de vista pragmático, aspecto que nos orienta aún más en la necesidad de situar el estudio de los «adverbios» en un planteamiento textual o discursivo. $\mathrm{O}$, al menos, ir pensando que la sintaxis debe trascender la oración y situarse en el texto, ya que también en esta dimensión se dan relaciones sintácticas que la mayoría de las veces son distintas de las que surgen dentro de una oración ${ }^{21}$.

Por otro lado, los disjuntos son aquellos que indican la actitud del hablante ante lo enunciado en la oración. Son marcadores de modalidad y aparecen normalmente en cabeza de la frase y entre pausas. Son parafraseables por estructuras de verbo ser + adjetivo. Probablemente = Es probable que..., como ya señaló Alarcos al hablar de los «atributos oracionales» ${ }^{22}$, que coinciden con estos.

También los de este grupo podrían ser mejor explicados tomando como base un análisis que supere la oración, ya que tampoco cumplen una función sintáctica delimitada. No podemos decir que probablemente en el ej. anterior: /3/: «Pro-

21 Algunos intentos en este sentido son los de Ducrot, Feuillet y S. Jacobson: «A new way of classifying adverbs». Acta Universitatis Lundensis, 1979, 30, pp. 123-134.

22 E. Alarcos Llorach: Estudios de gramática funcional del español. Madrid, Gredos, 3a edic., 1983, en «Aditamento, adverbio y cuestiones conexas». 
bablemente estará ahí», sea exactamente un adverbal, ya que lo que indica es probabilidad de toda la oración, inscribiéndola dentro de una determinada modalidad. Y esta se dirige hacia uno de los polos de la comunicación. Se sale de lo que es puramente mensaje, para convertirse en «actitud subjetiva del hablante».

Por lo tanto, mantenemos que no se puede seguir aislando la sintaxis de los agentes de la comunicación ni restringirla a su unidad mínima, ya que esas unidades mínimas también se relacionan para formar el todo intencional-comunicativo que es el texto, último objeto de un análisis de la lengua. Muchas voces han sido las que se han levantado actualmente para hacer constar esta realidad y desde muy diversas perspectivas. Nosotros no nos inscribimos en ninguna línea de las llamadas concretamente Lingüística del texto. Pensamos que en un análisis estructural funcional también hay que cambiar el punto que marca el límite del estudio y situarnos en el fenómeno comunicativo en toda su amplitud, porque la lengua se hace en y por la interrelación entre dos entes humanos. 
